\title{
Hepatocellular carcinoma: a new hope?
}

\author{
Lynn G. Feun \\ Department of Medicine, University of Miami, Miller School of Medicine, Miami, FL USA.
}

Correspondence to: Prof. Lynn G. Feun, Department of Medicine, University of Miami, Miller School of Medicine, Miami, FL, USA.E-mail: Ifeun@med.miami.edu

How to cite this article: Feun LG. Hepatocellular carcinoma: a new hope? Hepatoma Res 2019;5:26.

http://dx.doi.org/10.20517/2394-5079.2019.21

Received: 15 Jun 2019 First Decision: 17 Jun 2019 Revised: 18 Jun 2019 Accepted: 18 Jun 2019 Published: 12 Jul 2019

Science Editor: Guang-Wen Cao Copy Editor: Cai-Hong Wang Production Editor: Jing Yu

In this special issue of Hepatoma Research, we highlight certain Novel Approaches to Hepatocellular Carcinoma. In the article "Stereotactic ablative radiotherapy for hepatocellular carcinoma" Dr Spieler and Dr Portelance discussed the development of improved toxicity models and highly conformal radiation delivery systems which allows for stereotactic radiosurgery to ablate liver tumors in few fractions and spare noncancerous liver tissue ${ }^{[]]}$. Stereotactic body radiation therapy or SABR is an advanced form of external body radiation therapy. SABR combines both tumor/organ motion managment with multiple beams of high energy so that very high doses of radiation can be administered precisely in one to five fractions. Advantages to SABR is that this treatment is minimally invasive, can treat large tumor volume, or tumors close to liver capsule, major blood vessels or diaphragm and when disease is associated with portal vein thrombosis. This enables treatment for patients whose liver function tests may preclude radioembolization or chemoembolization, or when the portal vein is occluded which may preclude chemoembolization. In addition, as mentioned in the article, there is a rationale for this treatment to be considered to combine with immunotherapeutic agents to enhance response. Preclinical and clinical studies demonstrate that radiation therapy can upregulate $\mathrm{PD}-\mathrm{L} 1$ expression in tumors so checkpoint inhibitors may be more effective. Currently there are multiple clinical trials combining radiation therapy with checkpoint inhibitors such as anti-PD-1 or anti-PD-L1 inhibitors or with cytotoxic T-lymphocyte associate protein inhibitor (anti-CTLA-4) to treat hepatocellular carcinoma ${ }^{[2]}$.

In the case report of "Congenital absence of the portal vein complicated by hepatocellular carcinoma in the liver of an adult", Dr Mehta highlights the rarity of this condition ${ }^{[3]}$. There are only 101 previously reported cases of congenital absence of the portal vein and $40 \%$ of which were associated with hepatic tumors, including hepatocellular carcinoma. They discussed different approaches to treatment for patients

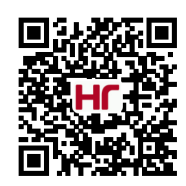


with this unusual anatomy and vasculature. This congenital abnormality represents a challenge for clinical management and should involve a multidisciplinary team experienced in the treatment of liver cancer.

Dr Ayoub and Dr Jones review the "Impact of nucleos $(\mathrm{t})$ ide analog therapy in hepatitis B on the incidence of hepatocellular carcinoma" ${ }^{\text {"[4] }}$. Hepatitis B is a major cause of hepatocellular carcinoma worldwide, particularly in the Far East. This article discusses the role of treatment of hepatitis B, including the new antiviral agents and how they may reduce but not eliminate the risk of hepatocellular carcinoma. The third generation nucleos $(\mathrm{t})$ ide analogs, tenofovir and entecavir, which both have a high genetic barrier to resistance, has led to further decreases in HCC incidence.

Finally, in the article "Immunotherapy for hepatocellular carcinoma: the force awakens in HCC?", we discuss newer therapeutic approaches with immunotherapeutic drugg ${ }^{[5]}$. It is known that hepatocellular carcinoma is an inflammation-associated malignancy and so can be immunogenic. Reasons for immune tolerance are included such as the presence in the liver of myeloid-derived suppressor cells, regulatory dendritic cells, T regulatory cells, invariant natural killer T- cells, and tumor-associated macrophages. Furthermore, there is evidence of T-cell exhaustion and apoptosis associated with chronic hepatitis C infection. Increased expression of TRAIL, indoleamine 2,3-dioxygenase (IDO), and LAG-3 have been found which may contribute to immunosuppression. In terms of therapy, recently, two checkpoint inhibitors, nivolumab and pembrolizumab, have been granted conditional approval for the treatment of hepatocellular carcinoma.

In the 2019 American Society of Clinical Oncology meeting, over 70 abstracts can be found under search for hepatocellular carcinoma and immunotherapy. Promising early results from clinical trials have been reported with combination of immunotherapy agents, or other modalities of treatment such as surgery or radiation therapy ${ }^{[6]}$. Thus, immunotherapy can now be considered, along with surgery, radiation therapy and chemotherapy, as a viable option and offers a new hope for our patients with hepatocellular carcinoma.

\section{DECLARATIONS}

\section{Authors' contributions}

Feun LG Contributed solely to the article.

\section{Availability of data and materials}

Not applicable.

\section{Financial support and sponsorship}

None.

\section{Conflicts of interest}

There is no conflict of interest.

\section{Ethical approval and consent to participate}

Not applicable.

\section{Consent for publication}

The author declared that there are no conflicts of interest.

\section{Copyright}

(c) The Author(s) 2019. 


\section{REFERENCES}

1. Spieler B, Mellon EA, Jones PD, Giap H, et al. Stereotactic ablative radiotherapy for hepatocellular carcinoma. Hepatoma Res 2019;5:4.

2. Stereotactic body (SBRT) followedy by immunotherapy in liver cancer. NCT 03203304 . Clinicaltrials. gov

3. Mehta A, Venkat SR, Portelance L, Feun LG. Congenital absence of the portal vein complicated by hepatocellular carcinoma in the liver of an adult woman: review of imaging, literature and management. Hepatoma Res 2018;4:7.

4. Ayoub WS, Dailey F, Martin P, Jones PD. The impact of nucleos(t)ide analog therapy in hepatitis B on the incidence of hepatocellular carcinoma: an update including recent literature findings. Hepatoma Res 2017;3:302-8.

5. Feun LG, Li YY, Wangpaichitr M, Wu CJ, Savaraj N. Immunotherapy for hepatocellular carcinoma: the force awakens in HCC? Hepatoma Res 2017;3:43-51.

6. Kaseb A, Pestana RC, Vence LM, Blando JM, Singh S, et al. Randomized, open-label, perioperative phase II study evaluating nivolumab alone or nivolumab plus ipilimumab in patients with resectable HCC. J Clin Oncol 2019;37:abstr4098 